\title{
Assessing early learning through formative assessment: key issues and considerations
}

\author{
Elizabeth Dunphy*
}

St Patrick’s College, Drumcondra, Ireland

\begin{abstract}
At all levels of education the assessment of learning is generally regarded as an integral part of teachers' work. For early childhood teachers, i.e., those who work with children in the age-range birth to six years, there are very particular considerations arising from the characteristics of young learners and the nature of early learning. This paper reviews the research on formative assessment of early learning and development. In doing so, it explores important theoretical constructs related to early learning and synthesises research related to key aspects of young children's learning. It discusses the methods that are most useful for developing rich pictures of early learning and development. Some of the challenges inherent in formative assessment in early childhood settings are also outlined and discussed.
\end{abstract}

Keywords: formative assessment; early childhood and development; professional knowledge; ethics

\section{Introduction}

At all levels of the education system assessment is growing in importance for educators' considerations of their work with children, but also in terms of their accountability to society. Furthermore, the principle that assessment informs teaching and that teaching involves assessing is considered as important in early childhood education (and care) ${ }^{1}$ as it is in other levels of the education system (Shepard, Kagan, and Wurtz 1998; Bowman, Donovan, and Burns 2001).

There is a long tradition of child observation in early childhood education. Many of the pioneers in the field (e.g., Froebel, Piaget, Vygotsky and Issacs) strongly promoted the processes of watching, listening and reflecting on children's actions and words. In recent decades there have been significant theoretical developments in relation to how we think about early learning (and development). ${ }^{2}$ Leading theorists (e.g., Anning, Cullen, and Fleer 2009) have documented and described the significance and challenges of sociocultural theories for all aspects of practice, including assessment. Tradition as well as recent advances in both theory and practice, together provide the foundations for contemporary approaches to assessment.

Both between and within countries, the heterogeneity that characterises early childhood education gives rise to differences in approaches to curriculum, to teaching and consequently to the assessment of early learning. In Ireland, as elsewhere, early childhood education takes place in a variety of settings including crèches, pre-schools, primary schools and family day-care settings. This leads to

*Email: Elizabeth.Dunphy@spd.dcu.ie 
considerable diversity in terms of access, funding, professional training and adultchild ratios and no doubt also results in considerable variations in quality from one context to another. In Ireland, the new national open-framework curriculum for early childhood education, The Framework for Early Learning (National Council for Curriculum and Assessment (NCCA) 2009) may help to bring some homogeneity to the quality of the learning experiences of children from birth to six years. The interrelatedness of curriculum and assessment (see Kelly 1992) makes it imperative and timely that issues and considerations related to the assessment of early learning now be addressed in Ireland, and in a manner that promotes coherence between the curriculum and the assessment of the learning that the curriculum seeks to promote. Indeed, there has to be a constant interplay between the curriculum and assessment 'in order to ensure the effectiveness of either' (Kelly 1992, 16). In recognition of this interplay, the NCCA will issue guidelines on assessment of early learning to accompany the curriculum when it is published.

This paper seeks to bring together key issues and considerations in relation to day-to-day assessment in diverse early childhood settings. Consideration of these issues can assist in theorising, stating and shaping/reshaping assessment practices, especially in countries such as Ireland where structures, curriculum and shared values are still emerging. On a practical level, this paper describes some of the most important methods and approaches used for formative assessment of early learning. A number of interesting issues, tensions and challenges arising from the material are explored and these are highlighted and discussed.

\section{A definition of formative assessment}

In the US, Bowman, Donovan, and Burns (2001) suggest that the term assessment, as applied in early childhood education, generally implies the intention to provide a rich picture of the ways in which young children act, think and learn. In the UK, Hurst and Lally (1992) describe how assessment involves educators in documenting, analysing and reflecting on the information collected, and using this to plan and support further learning. When the educator makes judgements about promoting children's learning based on the information gleaned through observation and interaction with them, then the assessment is considered to be formative, i.e., it promotes learning (see Gipps 1994; Torrance 2001). A recent large-scale longitudinal study of early learning settings in England confirmed the importance of formative assessment in meeting children's needs and in supporting their learning (SirajBlatchford et al. 2002). It is argued that assessment must work for young children:

\footnotetext{
We can use our assessments to shape and enrich our curriculum, our interactions, our provision as a whole: we can use our assessments as a way of identifying what children will be able to learn next, so that we can support and extend that learning. Assessment is part of our daily practice in striving for quality. (Drummond 1993, 13)
}

Thus the focus of this paper is on identifying and promoting approaches to formative assessment which are based on current ideas about early learning and which are coherent with open framework curricula. Approaches identified are those that can be used by educators of children aged birth to six years, as appropriate, in the range of educational settings. 
Characterising early learning

Assessment is about making the range of children's learning visible (Issacs 1930; Drummond 1993; Carr 2001). It is critical that it recognises the unique nature of development in early childhood. During early childhood children's learning across the various dimensions of development (e.g., physical, motor, linguistic, emotional) is greater than at any other period, but is also highly variable across the dimensions. It occurs very rapidly, is episodic in nature and very susceptible to environmental conditions (Shepard, Kagan, and Wurtz 1998).

Educators have consistently sought to convey the extent and complexity of early learning (see Athey 1990; Drummond 1993; Nutbrown 1999; Bowman, Donovan, and Burns 2001; Carr 2002). For instance the complexity of learning is demonstrated by the infant's engagement in communicating then, through language, in searching for meaning and understanding (see Wells 1986; Trevarthen 2002).This is the genesis of later literacy development. The presence of familiar sensitive and empathetic adults who are present and available to children from the earliest stages of life is a critical factor in enabling children's learning in the early stages (see Rogoff 1990, 1998).

Assessment is an ongoing process and involves observations of children in interesting, meaningful challenging and worthwhile experiences (Bowman et al. 2001; Meisels 1999; Torrance 2001). Many aspects of early learning are best assessed through close observation of children as they engage in everyday experiences in the early education setting. Such an approach is considered to be authentic since the tasks involved are carried out as part of everyday activity and are not especially designed for assessment purposes. This approach to assessment recognises the fact that curriculum and assessment are interwoven (Puckett and Black 2000).

Theoretical constructs related to early learning

Recently, a number of perspectives on learning have emerged all of which have particular resonance for early learning. They include the ecological perspective (Bronfenbrenner 1979; Bronfenbrenner and Morris 1998); the sociocultural perspective (Rogoff 1998); and the activity theory perspective (Engestrom, Meittenen, and Punamaki 1999). All these perspectives emphasise the socially constructed nature of learning and of assessment. They also emphasise the importance of the learning environment and of the context in which learning takes place. There are a number of important constructs that unite them to greater or lesser degrees. These include: children as collaborators; children's agency; children as co-constructers of meaning and knowledge. These constructs are particularly helpful when thinking about the quality of the interactions between educators and young learners. Quality interactions are increasingly recognised as central to all aspects of pedagogy, including assessment (Black and Wiliam 1998; Siraj-Blatchford et al. 2002).

\section{Children as collaborators in learning}

Vygotsky's theory of learning (1978) and in particular, his concept of the zone of proximal development provides the foundation for some of the most important 
recent initiatives in the assessment of individual children's learning (Lunt 2000). Berk and Winsler (1995) describe Vygotsky's zone of proximal development (ZPD) as:

... a dynamic zone of sensitivity in which learning and cognitive development occur. Tasks that children cannot do individually but they can do with help from others invoke mental functioning that are currently in the process of developing, rather than those that have already matured. (Berk and Winsler 1995, 26)

Adult-child collaboration within the ZPD is critical for effective teaching and learning interactions because it is within such interactions that the educator identifies how the child's learning may be assisted and what the child is capable of doing with appropriate support. The educator also has the opportunity to assess the impact of such support on the child's progress. Inter-subjectivity is where adult and child achieve a shared understanding whilst undertaking a task approached from different perspectives. Inter-subjectivity as achieved by adults and babies is different from that achieved by adults and children who can use linguistic (verbal and gestural) communication to achieve mutual understandings (Rogoff 1990, 1998). This then has implications for assessment processes in early childhood.

\section{Children's agency}

Agency is about taking more control of your own mental activity (Bruner 1996). Recognition of children's active management of their contributions in participation with adults in social activity is a cornerstone of socio-cultural activity (see Rogoff 1990, 1998). From this perspective, young children's agency has two dimensions: that related to their efforts to play an active role in adult activities and also their efforts to get adults' help when they need it. Rogoff observes how, in social interactions, children manage both their own roles and those of adults. She also stresses, drawing on the work of others, that there is the possibility for them to be more agentic in situations where there is no deliberate attempt to teach, i.e., in 'non-contrived situations' (1990, 99). Children, including infants in the first year of life, can sometimes be observed to be deliberately taking the lead in collaborative activities by seeking information or by directing activities (Rogoff 1990, 1998). Children often initiate such activity (Rogoff 1998), for example in seeking to help the adult in everyday chores. Older toddlers and young children will seek to assert their independence in doing a particular task for themselves but Rogoff 's analysis of the research suggests that they also will actively seek assistance when they encounter a problem. The extent to which children can exert their agency is culturally determined (Rogoff 1990). In some cultures children are expected not to get involved in adult activities or to actively question adults, whereas in others children frequently engage in social activity alongside adults and are free to make demands within social situations. Of course, the ultimate way in which children assert their agency is by determining the direction of their attention.

Context, both interpersonal and sociocultural, is a key issue in relation not only to what children may learn but also to the extent to which young children exercise agency. The interpersonal dimension is a critical feature of the earliest stages of social interaction and it seems that when very young babies engage in communication exchanges with familiar adults it is often based on mutual imitation. As adults seek to engage with infants, they have been observed to respond by imitating selected 
aspects of their behaviour. The infant often rewards the adult's attention by expressing joy in various ways. In this way, very young babies act in an agentive way 'shaping the adults' behaviour even as their own behaviour is shaped by the adults' editing' (Parker-Rees 2007, 9).

The understanding of young children's relationships with each other is also key in recognising and assessing early learning. For instance, young children (aged 14- to 30 -months) have been seen to develop communication with other children, and vary their imitations of other children's behaviours, thus demonstrating collaboration and agency (Lindahl and Pramling Samuelsson 2002).

\section{Children as co-constructors of meaning and knowledge}

In New Zealand, Smith (1999) researched the incidence of joint attention episodes between infants and toddlers and their care givers in child care centres. Significantly, smaller group size and higher levels of training amongst educators were both factors associated with higher levels of joint attention. About one third of children in the study participated in no joint attention episodes, thus suggesting limited opportunity for co-construction of understanding with educators. Co-construction refers to adults and children making meaning and knowledge together (MacNaughton and Williams 2004). Co-construction and the establishment of 'sustained shared thinking' between educator and child were found to be key factors in promoting the learning of children aged three-five years (Siraj-Blatchford et al. 2002). Essentially a co-construction perspective recognises the child's perspective and emphasises understanding and meaning on the part of child and adult, rather than the acquisition of facts by the child (Jordan 2009).

In summary, an understanding of the different processes that contribute to children's learning, and the types of interactions that promote it, are central to understanding how learning can best be recognised and assessed, and how children themselves play a key role in the assessment process.

Key aspects of early learning

Recently there have been a number of examples of curricula where certain aspects of early learning are given prominence above others. For example, dispositions; a range of cognitive abilities; emotional well being; and self concept and sociability are all examples of aspects of learning which have been foregrounded. Such an approach to curriculum has implications for assessment. Each of these are discussed below.

\section{Dispositions}

Dispositions have emerged as central in the debate about what is of lasting value in learning. Dispositions are regarded as 'relatively enduring habits of mind and action, or tendencies to respond to categories of experience across classes of situations' (Katz and Chard 1992, 30). They dispose learners to interpret, edit and respond to learning opportunities in characteristic ways (Carr 1999). Desirable dispositions might include perseverance, risk-taking and curiosity. Helplessness is an example of an undesirable disposition. Young children (under five years) already display learning dispositions which in some cases support optimum learning, for example 
where they display an orientation towards learning goals and a consequent tendency towards persisting and having a go. In other cases dispositions may serve as obstacles, for example where they display an orientation towards performance goals and a consequent tendency to avoid taking a risk to avoid making a mistake (Smiley and Dweck 1994). Specific dispositions, for example flexibility, positive affect and intrinsic motivation, can be developed and observed in social pretend play (Pellegrini 1998). In New Zealand, the national early childhood curriculum Te Whariki (Ministry of Education (MoE) 1996) explicitly foregrounds dispositions, while in England The Statutory Framework for the Early Years Foundation Stage (Department for Children, Schools and Families 2008) also draws specific attention to dispositions.

Children play an active role in the development of their dispositions through participation and collaboration. Indeed, Rogoff $(1990,171)$ draws our attention to what she refers to as 'the essential nature of children's own eagerness to partake in ongoing activity'. Carr (2001) describes the process of assessing dispositions as one of assessing complex and elusive outcomes. While it seems essential to focus on children's developing dispositions, from the assessment perspective there is the difficulty of deciding on which dispositions to name and assess. Even if consensus on this question was achieved there is still the challenge of tracking dispositions (Claxton and Carr 2004). This appears to be well beyond practice currently undertaken in the day-to-day activity of many early education settings generally (see Anning, Cullen, and Fleer 2009; Shepard, Kagan, and Wurtz 1998).

\section{A range of cognitive abilities}

The desire to develop a new means of assessing the cognitive abilities of pre-school children provided the impetus for Project Spectrum, a research and development project based on the theories of Gardner (1993) and Feldman (1994). Both theories emphasise a broader view of human cognition than that offered by previous theories. Krechevsky describes how Gardner's theory emphasises a wide range of intelligences which had not been not previously identified or documented in assessing early learning, while Feldman articulated a theory of universal and non-universal domains of development. During the course of the project, curriculum and assessment materials were devised, and these 'tapped a wider range of cognitive and stylistic strengths than typically had been addressed in early childhood programmes' (Krechevsky 1998, 1). Gardner (1999) describes how children are surveyed in a variety of intellectual domains (movement, language, mathematics, science, social, visual art and music). Specific tasks and measures that are engaging to children, for example mathematical games in the case of mathematics, are introduced in the course of natural classroom activity and children are assessed using these. Observations of children in potentially challenging situations that arise in the ordinary course of events (for example, an argument with another child) are also regarded as appropriate in assessing certain areas of development. The Spectrum system of assessment claims to embed assessment in authentic activity and so to blur the lines between curriculum and assessment; to attend to the stylistic dimensions of performance; to use measures that are intelligence-fair; and to avoid using language or logic as assessment vehicles (Krechevsky 1998). Focusing on a range of cognitive abilities for assessment purposes would appear to require considerable amounts of 
time to carry out assessments and consequently may not appeal to educators who may view them as too onerous.

\section{Emotional well-being}

In Belgium, and to a lesser extent elsewhere, educators use the Experiential Education (Laevers 2000) model, which focuses on children's experiences in the educational setting. It involves carrying out systematic observations of children using well-being and involvement scales at least three times a year. It is argued that wellbeing and involvement of children are key to learning and enable children to enter into a 'flow' state, i.e., 'a manifest feeling of satisfaction and a stream of energy felt throughout the body .... Young children usually find it in play' (Laevers 2000, 245). As a result learning that affects deep structures on which competencies and dispositions are based is enabled (Laevers 2000). A limitation of the foregrounding of emotional well-being is that this approach may offer too little in terms of specifying the 'what' of learning, particularly for children at the upper end of the birth to six age range. Indeed, in this context a point made by Adams, Alexander, Drummond and Miles is worth noting. They argue, in the context of their review of how the (then) new Foundation Stage Curriculum in England was changing the experiences of four-year-old children in reception classes, that:

When children are demonstrably secure, happy, confident, even joyful, it is not necessarily an easy task to ask oneself whether they are, in fact, experiencing a challenging and worthwhile curriculum. (Adams et al. 2004, 27)

\section{Self-concept and sociability}

The ability to get along with others and to establish positive relationships is a key aspect of early learning. While initially the family is the main influence on the development of social abilities, as children begin to move out of the immediate family peer interactions become increasingly important. Pellegrini (1998) argues that understanding of salient points in children's social development is critical. Educators also need to understand the different roles played by temperament, socio-cognitive skills, communication skills and family and peers in the development of sociability. They need to take account of the multiple influences on children's play (where, with whom, with what objects) since all of these contextual factors affect children's learning, as do peer relations and peer-group dynamics (Fabes, Gaertner, and Popp 2006).

It appears that in the most effective settings educators 'supported children in being assertive, at the same time as rationalising and talking through their conflicts' (Siraj-Blatchford et al. 2002, 12). For example, the use of story books and group discussions to work through common conflicts, and the subsequent documentation of children's reactions and interactions can provide important evidence of learning. Also in the UK, Broadhead's (2004) work explicates the links between intellectual development, the growth of language and the emotional well-being of children. Her Social Play Continuum offers the educator an observation tool; a tool for assessing children's social development; and a means of developing children's sociability. It focuses on children's play activity and their language across the age range three to six 
years and it illustrates the increasingly complex ways in which children are able to operate socially and cooperatively. A limitation of foregrounding self concept and sociability in terms of curriculum and assessment is that other aspects of learning may be overlooked.

In Ireland, The Framework for Early Learning (NCCA in press) describes early learning in terms of the themes of well-being; identity and belonging; communicating; and exploring and thinking. These closely echo the themes of Te Whariki, the New Zealand early childhood curriculum (MoE 1996). Thus if assessment and curriculum are aligned, when educators in Ireland assess learning they will need to look for evidence of development and learning in relation to each of these themes.

Methods and approaches in assessing early learning

Assessing learning involves a number of processes. These include observing and empathising; communicating; interviewing; documenting and reflecting on learning; compiling portfolios; and developing narratives about learning. Often, these processes need to be engaged in concurrently and they are best undertaken in authentic contexts.

\section{Observing and empathising}

Observation has long been recognised as key to uncovering children's learning, the meaning of their actions, their mark-making and their words. Drummond (2000) describes how Issacs put her rich observational data related to what children did, thought and felt to excellent use in drawing it together 'to construct a coherent account of the development of children's intellectual and emotional powers'. Issacs wrote narrative accounts, and this approach continues to be developed and refined in the modern context. However, in some instances, educators also use checklists to record their observations and assessments. While these may serve some purpose in relation to assessing the development of specific knowledge or skills they cannot give a comprehensive account of children's learning. Details regarding the critical issues of context, interactions and relationships are not considered (see Carr 2001; Fleer and Richardson 2004). Without these it is impossible for the educator to understand either the perspective or intent of particular children in the assessment situation. They cannot convey the extent and richness of young children's learning (see Drummond 1993; Bowman, Donovan, and Burns 2001).

Educators who have close personal relationships with children are the people best placed to make observations of their learning. Recognising and seeking to understand children's emotional signals is important, as are interpretations of children's messages as expressed through their body language and non-verbal and verbal behaviour (MacNaughton and Williams 2004). Goldschmied and Jackson (2004) describe how close relationships provide the context within which children are most likely to seek appropriate support from adults and so communicate and progress their learning. However, understandings of infants' behaviour are to a large extent influenced by educators' theories and beliefs and these in turn are influenced by theoretical knowledge (Degotardi and Davis 2008). For instance, Goldschmied and Jackson (2004) argue that knowledge of core developmental lines (for example mobility, manipulative skill, feeding and bodily care, and the acquisition of the ability to 
communicate in words) is essential for educators. Such knowledge, mediated by sensitivity to culture and context, can certainly enable educators in assessing learning.

\section{Communicating}

Day-to-day conversations provide rich contexts for assessments of learning. Educators listen carefully in order to understand what the child is seeking to communicate, either through gesture, behaviour or language (MacNaughton and Williams 2004). Skilful use of questioning during conversations can elicit children's theories and understandings, enabling them to share feelings and engaging them in speculation and imaginative thinking (see Fisher 1990; Wood 1998; Siraj-Blatchford and Clark 2003). Research indicates that for pre-school children, non-verbal signs are crucial for communication. It appears that three-year-old children co-construct meaning with adults 'not only through words, but also through gaze, facial expression, and body movements' (Flewitt 2005, 220). For example, gestures such as imitating actions, intentionally using gaze, touching, and pointing have been identified as key modes of expression and communicating. These often accompany talk and supplement children's linguistic resources and abilities. The implication of this for assessment is that educators must be sensitive to this multi-modal dimension of children's expressions of meaning making. While multi-modality is a feature of children's expression of meaning, it is also a feature of their representations of meaning: multimodality is core to children's preferred ways of representing and communicating their growing understanding of the world and their roles as active members of communities (Anning and Ring 2004, 124).

Children's drawings can be understood 'as their personal narratives which they use to order and explain the complexity and their experiences of the world' (Anning and Ring 2004, 5). Mark making should always be considered to be intentional and the analysis and discussion of mark making and drawings can convey a great deal about children's emerging understandings of many aspects of their world as for example, in the area of numeracy (Worthington and Carruthers 2003). However, there are also occasions when educators need to ascertain information about learning which is not evident from the child's performance in everyday activity. Interviewing children is more formal than everyday conversation but is a process that can be both flexible and responsive.

\section{Interviewing}

Variations on what is known as 'the clinical interview' have been identified as important in the search for new approaches to the assessment of early learning (Bowman, Donovan, and Burns 2001). The clinical interview, as a method, has been developed over the years since first used by Piaget (1997). It is especially of interest when traditional methods of enquiry, such as observation, are inadequate to uncover children's thinking. During the interview, the educator 'acts as clinician in judging how to respond to different children by being sensitive to the nuances of individual needs' (Ginsburg 1997, 140). Doverberg and Pramling (1993) describe their approach to interviewing young children as one in which reciprocity and mutual turn-taking in communicating is established and both the interviewer and the child become significantly involved in the development of the conversation. One of the strengths of 
the method is that it can be used to assess both cognitive and affective aspects of children's understandings, including dispositions. Dunphy (2006) argues that interviewing is within the reach of educators in terms of the time commitment required. This is an important consideration since previous research has found that methods that required lengthy observations did not work for busy educators (Fleer and Richardson 2004).

\section{Documenting and reflecting}

In recent years documentation practices in early childhood education have been greatly advanced by educators in Reggio Emilia in Italy (Edwards, Gandini, and Forman 1998). Rinaldi (1998) suggests that their approach to documentation offers the educator the unique opportunity to listen again to young children and reflect on the learning processes as revealed by children. The 'mosaic approach' to listening to children uses a variety of tools to enable children to convey their ideas and feelings in a range of symbolic ways as co-constructors with adults of meaning (Clark and Moss 2001, 3).

\section{Compiling portfolios}

Portfolios are purposeful collections of evidence of early learning and of children's progress in relation to the learning goals of the curriculum. They offer a practical approach to assembling and organising the range of information on children's learning (Puckett and Black 2000). In the case of babies and toddlers, the responsibility is on the educator (generally in conversation with parents or guardians) to select the information that will be compiled as a record of learning. As soon as they can, children should be encouraged to participate in the selection process with adults. Digital cameras and audio and video recorders, offer considerable potential to enhance the range of material and information that can be assembled about children's early learning (Boardman 2007). These digital technologies are also a useful way of collecting and presenting a great deal of information about a child's early learning in a succinct form. The material thus compiled has a number of functions: it can be the basis for adult/child conversations; it can be central in providing information to parents or guardians; it can be the basis for reflection, either by the educator alone or with colleagues; and it can be the focus for planning activities based on what is known about the child.

The processes of compiling, talking about and sharing portfolio work will also contribute to children's ability to think and talk about their own learning and that of others - helping them to become meta-cognitively aware (Bruner 1999a). It also involves children in the process of self-assessment wherein they begin to be aware of goals for learning and of the possibility of setting their own goals, and reflecting on and making judgements about their own progress towards those goals (Moyles 1989, 125-6).

\section{Developing narratives about learning}

Narrative or story approaches have been used by educationalists both to understand aspects of teaching and learning and to communicate this to others. Bruner (1999b, 
175) describes narrative as 'a mode of thought and a vehicle for meaning making' cautioning however that narrative accounts of learning are not ends in themselves, but must be used as tools for reflection and for sharing with others in order to seek out possible other meanings. In the US, Paley (e.g., 1979) has made extensive use of narrative to share her ethnographic observations of children. Her use of the taperecorder illustrates how reflection can be achieved even in a busy early education setting and especially how it can be done in discussion with children. Carr (2001) and her colleagues developed the 'learning stories' approach to documenting children's learning. This approach was developed in response to a need to develop a pedagogy that was consistent with new conceptualisations of early learning as encapsulated in Te Whariki, the New Zealand early childhood curriculum (MoE 1996). Learning stories are 'structured observations, often quite short, that take a "narrative" or story approach. They keep the assessment anchored in the situation or action' (Carr 2000, 32).

The approach is rooted in the 'activity theory' perspective on learning as articulated by Engestrom, Meittenen, and Punamaki (1999). It takes a holistic view of learning and so gathers evidence in relation to children's developing dispositions and also their achievements and their progress over time (Carr 2002). It is argued that the story approach potentially offers 'respectful accounts of young learners and their learning as well as accounts that support future learning' (Hall and Burke 2003, 143). However it is not without its challenges. Documenting learning stories is demanding, as is making sense of the information and deciding on its implications for planning further learning experiences (Carr 2001). Also, from a sociocultural perspective, it is important to avoid focusing only on the individual child, but to attend also to the social and cultural aspects of the situation and to consider these when appraising the learning (Fleer 2002; Fleer and Richardson 2004).

\section{A fully-contextualised account of learning}

Meisels (1999) argues strongly for a dual focus on the child and on the environment in which the child is learning. His interactionist view draws attention to the fact that children are in interaction with the learning environment and they change the environment (as a result of actions and interactions) and the environment influences what they can accomplish. Fleer (2002) argues that the extent to which educators would, in reality, move beyond an individualistic account of learning whilst using the story approach to assessment is questionable. Her position is that a truly sociocultural approach takes into account all of the aspects of the situation in which the assessment takes place. It describes the whole learning journey of the group of children, rather than individuals (Fleer and Richardson 2004). In doing so, a number of aspects of the situation are recorded. These include the intentional interactions, the adult modelling, the use of cultural tools (for example, writing), the child-educator interactions and the child-child interactions. However, moving from an individualistic approach to a sociocultural one is a major paradigmatic shift, and while essential, presents many challenges to early childhood educators (Fleer and Richardson 2004; Edwards 2007). 
Challenges in formative assessment of early learning

A number of challenges to formative assessment in early learning have been identified. First, in the area of professional knowledge, the importance of educators having a comprehensive understanding of early development and learning is stressed (Bowman, Donavan, and Burns 2001). This includes an understanding of diversity, content matter and pedagogical content knowledge as well as how authentic assessment can be carried out (Espinosa 2005; Shulman 1999; Shepard, Kagan, and Wurtz, 1998; Puckett and Black 2000). Second, formative assessment must be manageable in terms of the time that is available to conduct observations, conversations and documentation (Ridgway 2001; Fleer and Richardson 2004). Third, educators need to take account of ethical considerations related to consultation with parents as well as children, including trusting that young children can exercise their voice in a meaningful way. This also includes sensitivity to the cultural and linguistic background of children, and that assessments are deemed to be fair and reflective of the whole person of the child (Siraj-Blatchford and Clark 2003).

Educators need not only an extensive understanding of early learning but equally knowledge of the genesis of culturally important areas of learning such as literacy and numeracy and a knowledge of how to make these accessible to even the youngest children. At the upper age-range (children aged four to six) undoubtedly a tension can exist between subject-specific assessments and more holistic assessments. The educator may be faced with the dilemma of how to focus on holistic issues of importance such as self-concept and creativity while at the same time focusing on subject-specific learning such as levels of phonological awareness, or knowledge of numbers. A further tension exists between the use of what educators might consider the more manageable tools for observation of learning such as checklists and the use of more time-consuming tools such as learning stories. The danger is that educators may, in the course of a busy day, find it more manageable to use the less demanding tool (checklists) rather than compiling rich and potentially more useful narrative accounts of children's learning (learning stories).

\section{Conclusion}

At the core of this paper is the principle that assessment in early childhood is about making the range of children's early learning visible. This can be achieved through the processes of collecting information about children's learning, documenting that information, reflecting on it and then using the information to support and extend learning. We have also seen that the character and complexity of early learning necessitates the employment of methods that will allow for the development of suitably rich accounts of children's early learning. It appears that a narrative approach is one that offers educators a way of providing a rich picture of early learning through documenting particular instances of learning; a focus for reflecting on learning; and a rationale for making decisions regarding provision. It is also a way of communicating with others about children's learning. However, we have also seen that narrative approaches are challenging to implement in practice.

The paper also highlights the extent of the understandings and the range of skills needed by educators in order for them to engage in assessing early learning, 
including not only a focus on how children learn but also an awareness of diversity among children, especially with respect to culture and language. The relationship between educator and individual children, as well as their parents is also highlighted as central. Recognising and acknowledging the role that children themselves play in the process may, for some educators, present a new perspective on assessing early learning. The challenges identified relate both to professional preparation and development and to the structural issue of adult: child ratios. These must be addressed by governments as a first step in any serious attempt to develop high quality education for the youngest children.

\section{Acknowledgements}

This paper is based on Supporting early learning and development through formative assessment, a background paper commissioned by the NCCA. The paper was written in the period October-December 2007 and the author wishes to acknowledge the valuable feedback provided by the NCCA in developing it.

\section{Notes}

1. For the purpose of this article the terms education and care are considered to be synonymous.

2. For the purpose of this article the terms learning and development are considered to be synonymous.

\section{Notes on contributor}

Elizabeth Dunphy is a senior lecturer in Early Childhood Education. Her research interests include eliciting children's perspectives, young children's learning, early childhood mathematics, and pedagogy in early childhood education. Articles previously published in Irish Educational Studies focussed on the mathematics curriculum for infant classes and its potential to develop children's number sense, and also on improving pedagogy in infant classes.

\section{References}

Adams, S., E. Alexander, M. Drummond, and J. Moyles. 2004. Inside the foundation stage: Recreating the reception year. London: Association of Teachers and Lecturers. http:// www.atl.org.uk/atl_en/education/learning.asp

Anning, A., J. Cullen, and M. Fleer. 2009. Early childhood education: Society and culture. London: Sage Publications.

Anning, A., and C. Ring. 2004. Making sense of children's drawings. Milton Keynes: Open University Press.

Athey, C. 1990. Extending thought in young children: A parent-teacher partnership. London: Paul Chapman.

Berk, L., and A. Winsler. 1995. Scaffolding children's learning: Vygotsky and early childhood education. Washington, DC: National Association for The Education of Young children.

Black, P., and D. Wiliam. 1998. Assessment and classroom learning. Assessment in Education 5, no. 1: 7-73. www.ebscohost.com

Boardman, M. 2007. 'I know how much this child has learned. I have proof!' Employing digital technologies for documentation processes in kindergarten. Australian Journal of Early Childhood 32, no. 3: 59-66.

Bowman, B., S. Donovan, and S. Burns. 2001. Eager to learn: Educating our pre-schoolers. Report of Committee on Early Childhood Pedagogy, Commission on Behavioral and Social 
Sciences and Education National Research Council. Washington, DC: National Academy Press.

Broadhead, P. 2004. Early years play and learning: Developing social skills and cooperation. London: Routledge.

Bruner, J. 1996. The culture of education. Cambridge, MA: Harvard University Press.

Bruner, J. 1999a. Folk pedagogies. In Learners and pedagogy, ed. J. Leech and B. Moon, 4-20. London: Paul Chapman Publishing.

Bruner, J. 1999b. Culture, mind and education. In Curriculum in context, ed. B. Moon and P. Murphy, 148-78. London: Paul Chapman Publishing.

Bronfenbrenner, U. 1979. The ecology of human development. Cambridge, MA: Harvard University Press.

Bronfenbrenner, U., and P. Morris. 1998. The ecology of developmental processes. In Handbook of child psychology: Theoretical models of human development, ed. W. Damon and R. Lerner, 993-1029. New York: John Wiley.

Carr, M. 1999. Being a learner: Five learning dispositions for early childhood. Early Childhood Practice 1: 82-99.

Carr, M. 2000. Let me count the ways (to do assessment). Proceedings of The Practice, Policy and Politics Conference, Victoria University of Wellington, 9-12 July 2000. New Zealand: New Zealand Educational Institute.

Carr, M. 2001. Assessment in early childhood settings: Learning stories. London: Paul Chapman Publishing.

Carr, M. 2002. Emerging learning narratives: A perspective from early childhood education. In Learning for life in the twenty-first century, ed. G. Wells and G. Claxton, 99-111. Oxford: Blackwell.

Clark, A., and P. Moss. 2001. Listening to young children: The mosaic approach. London: National Children's Bureau.

Claxton, G., and M. Carr. 2004. A framework for teaching learning: The dynamics of disposition. Early Years 24, no. 1: 87-97.

Degotardi, S., and B. Davis. 2008. Understanding infants: Characteristics of early childhood practitioners' interpretations of infants and their behaviours. Early Years 28, no. 3: 221-34.

Department for Children, Schools and Families (DCSF). 2008. Statutory Framework for the Early Years Foundation Stage (revised). Nothingham: DCSF Publications.

Doverberg, E., and I. Pramling. 1993. To understand children's thinking: Methods for interviewing children. University of Goteborg: Department of Methodology, Report No. 5.

Drummond, M.-J. 1993. Assessing children's learning. London: David Fulton Publishers.

Drummond, M.-J. 2000. Comparisons in early years education: History, fact and fiction. Early Childhood Research and Practice 2, no. 1. http://ecrp.uiuc.edu/v2n1/drummond.html

Dunphy, E. 2006. An exploration of young children's number sense on entry to school in Ireland. Milton Keynes: Open University.

Dunphy, E. 2008. The framework for early learning: A background paper. Supporting early learning through formative assessment. http://www.ncca.ie/uploadedfiles/Primary/EC_ assessment_paper2.pdf

Edwards, S. 2007. From developmental constructivism to socio-cultural theory and practice. Journal of Early Childhood Research 5, no. 1: 83-106.

Edwards, C., L. Gandini, and G. Forman. 1998. The hundred languages of children: The Reggio Emilia approach-advanced reflections. London: Ablex Publishing Corporation.

Engestrom, Y., R. Meittenen, and R. Punamaki. 1999. Perspectives on activity theory. Cambridge: Cambridge University Press.

Espinosa, L. 2005. Curriculum and assessment considerations for young children from culturally, linguistically and economically diverse backgrounds. Psychology in the Schools 42, no. 8: 837-53.

Fabes, R., B. Gaertner, and K. Popp. 2006. Getting along with others: Social competence in early childhood. In Blackwell handbook of early childhood development, ed. K. McCarthy, and D. Phillips, 297-316. Oxford: Blackwell Publishing.

Feldman, D. 1994. Beyond universals in cognitive development. Westport, CN: Ablex Publishing.

Fisher, R. 1990. Teaching children to learn. Oxford: Basil Blackwell. 
Fleer, M. 2002. Socio-cultural assessment in early years education-myth or reality? International Journal of Early Years Education 10, no. 2: 105-19.

Fleer, M., and C. Richardson. 2004. Mapping the transformation of understanding. In Early childhood education: Society and culture, ed. A. Anning, J. Cullen, and M. Fleer, 119-33. London: Sage Publications.

Gardner, H. 1993. Multiple intelligences: The theory in practice. New York: BasicBooks.

Gardner, H. 1999. Assessment in context. In Learners, learning and assessment, ed. P. Murphy, 90-117. London: Open University.

Ginsburg, H. 1997. Entering the child's mind: The clinical interview in psychological research and practice. New York: Cambridge University Press.

Gipps, C. 1994. Beyond testing: Towards a theory of educational assessment. London: Falmer Press.

Goldschmied, E., and S. Jackson. 2004. People under three: Young children in daycare. New York: Routledge.

Hall, K., and W. Burke. 2003. Making formative assessment work: Effective practice in the primary classroom. Milton Keynes: Open University Press.

Hurst, V., and M. Lally. 1992. Assessment and the nursery curriculum. In Assessment in early childhood education, ed. G. Blenkin and A. Kelly, 46-68. London: Paul Chapman Publishing.

Issacs, S. 1930. Intellectual growth in young children. London: Routledge.

Jordan, B. 2009. Scaffolding learning and co-constructing understandings understanding. In Early childhood education: Society and culture, ed. A. Anning, J. Cullen, and M. Fleer, 31-42. London: Sage Publications.

Katz, L., and S. Chard. 1992. Engaging children's minds: The project approach. Norwood, NJ: Ablex Publishing Corporation.

Katz, L., and S. Chard. 1996. The contribution of documentation to the quality of early childhood education. ERIC Digest, April, EDO-PS-96-2.

Kelly, A.V. 1992. Concepts of assessment: An overview. In Assessment in early childhood education, ed. G. Blenkin and A.V. Kelly, 1-23. London: Paul Chapman Publishing.

Krechevsky, M. 1998. Project spectrum: Pre-school assessment handbook. New York: Teachers College Press.

Laevers, F. 2000. Forward to basics: Deep-level-learning and the experiential approach. Early Years 20, no. 2: 20-9.

Lindahl, M., and I. Pramling Samuelsson. 2002. Imitation and variation: Reflections on toddlers' strategies for learning. Scandinavian Journal of Educational Research 46, no. 1: 25-45.

Lunt, I. 2000. The practice of assessment. In Educational activity after Vygotsky, ed. H. Daniels, 145-70. London: Routledge.

MacNaughton, G., and G. Williams. 2004. Techniques for teaching young children: Choices in theory and practice. Melbourne: Addison Wesley Longman.

Meisals, S.J. 1999. Assessing readiness. In The transition to kindergarten, ed. R. Pianta and M. Cox, 39-66. Baltimore, MD: Paul Brooks Publishing.

Ministry of Education. 1996. Te Whariki: Early childhood curriculum. Wellington: Learning Media.

Moyles, J. 1989. Just playing? The role and status of play in early childhood education. Milton Keynes: Open University Press.

National Council for Curriculum and Assessment. In press. The framework for early learning. Dublin: NCCA.

Nutbrown, C. 1999. Threads of thinking. London: Paul Chapman Publishing.

Paley, V. 1979. White teacher. Cambridge, MA: Harvard University Press.

Parker-Rees, R. 2007. Liking to be liked: Imitation, familiarity and pedagogy in the first years of life. Early Years 27, no. 1: 3-17.

Pellegrini, A. 1998. Play and the assessment of young children. In Multiple perspectives on play in early childhood education, ed. O. Saracho and B. Spodek, 220-39. Albany, NY: State University of New York Press.

Piaget, J. 1929. The child's conception of the world. London: Routledge.

Puckett, M., and J. Black. 2000. Authentic assessment of the young child. USA: Prentice Hall. 
Ridgway, M. 2001. Towards the integration of teaching, learning and assessment: A study of junior classes in selected Cork city schools. Ph.D. diss., National University of Ireland, Cork.

Rinaldi, C. 1998. Projected curriculum constructed through documentation - progettazione: An interview with Lella Gandini. In The hundred languages of children: The Reggio Emilia approach-advanced reflections, ed. C. Edwards, L. Gandini, and G. Forman, 113-25. London: Ablex Publishing Corporation.

Rogoff, B. 1990. Apprenticeship in thinking: Cognitive development in social context. New York: Oxford University Press.

Rogoff, B. 1998. Cognition as a collaborative process. In Handbook of child psychology, ed. W. Damon, 679-744. New York: John Wylie.

Shepard, L., S. Kagan, and E. Wurtz. 1998. Principles and recommendations for early childhood assessments. Washington, DC: National Education Goals Panel.

Shulman, L. 1999. Knowledge and teaching: Foundations of the new reform. In Learners and pedagogy, ed. J. Leach and B. Moon, 61-77. London: Paul Chapman Publishing.

Siraj-Blatchford, I., and P. Clark. 2003. Supporting identity, diversity and language in the early years. Milton Keynes: Open University Press.

Siraj-Blatchford, I., K. Sylva, S. Muttock, R. Gilden, and D. Bell. 2002. Researching effective pedagogy in the early years (REPEY): DFES (Department for Education and Skills) research report 356. London: DFES, HMSO.

Smiley, P., and C. Dweck. 1994. Individual differences in achievement goals among young children. Child Development 65: 1723-43.

Smith, A. 1999. Quality childcare and joint attention. International Journal of Early Years Education 7, no. 1: 85-98.

Torrance, H. 2001. Assessment for learning: Developing formative assessment in the classroom, Education 3-13 October: 26-32.

Trevarthen, C. 2002. Learning in companionship: Education in the North. The Journal of Scottish Education 10: 16-25.

Vygotsky, L. 1978. Mind in society. Cambridge, MA: Harvard University Press.

Wells, G. 1986. The meaning makers. London: Hodder and Stoughton.

Wood, D. 1998. How children think and learn: The social context of cognitive development. Oxford: Blackwell.

Worthington, M., and E. Carruthers. 2003. Children's mathematics: Making marks, making meaning. London: Paul Chapman Publishing. 